\title{
Tapping of Magmas from Ubiquitous Mantle Heterogeneities: An Alternative to Mantle Plumes?
}

\author{
NORMAN H. SLEEP \\ Departments of Geology and Geophysics, Stanford University, California
}

\begin{abstract}
Long-lived heterogeneities in the mantle are indicated by $\mathrm{Nd}-\mathrm{Sr}-\mathrm{Pb}$ isotopic systematics. Explanations for these variations have invoked either distinct layers in the earth that are preferentially tapped by some source regions (such as plumes rising from the base of the mantle) or small-scale heterogeneities which are ubiquitously distributed through the mantle and tapped differentially in various source regions. Consideration of the thermal and mechanical aspects of the latter hypothesis provides an explanation for the differences between mid-oceanic ridge basalts and off-axis volcanism. The melting behavior in a region with heterogeneities is modified by lateral conduction of heat, so that the first melted regions are tapped preferentially at off-axis volcanoes where small degrees of melting occur. A small (less than a few kilometers), easily melted heterogeneity draws heat from its surroundings as it melts during ascent. An increase of melting by a factor of 2 over adiabatic ascent is probable in the most easily melted regions if the melted and unmelted regions have comparable volume. The increase is larger in the earliest stages if melting is confined to small isolated heterogeneities. The depleted isotopic ratios of mid-oceanic ridge basalts can be explained as follows. Heterogeneities with enriched components melt before those with depleted components as material ascends beneath the ridge. Then the enriched melts are removed from the source region before mid-oceanic ridge basalts are tapped. The first enriched components to melt enter fractures that carry them upward and outward away from the source region of basalts at the ridge axis. This occurs because the direction of shear strain in the upwelling is such that the axis of tension plunges at $45^{\circ}$ away from the ridge axis and dikes of melt propagate up perpendicular to the axis of tension. In contrast with the ridge, volcanoes away from the ridge axis preferentially tap the earlier melted components. At the greater source depths of these volcanoes only non-mid-oceanic ridge basalt (MORB) components are significantly molten. Another enriched off-axis source region is the layer formed by the first enriched magma which moved laterally and avoided the source region of basalts at the ridge axis. For small-scale ubiquitous heterogeneities to explain the differences between mid-oceanic ridge basalts and off-axis volcanism, the MORB component must produce a greater volume of melt than the other components. If isotopic mass balances preclude the MORB component from being this abundant in the whole mantle, then the lower mantle is probably a separate reservoir from the upper mantle. In that case, it is conceivable that passive ubiquitously distributed blobs derived from the lower mantle at earlier times act as small-scale heterogeneities. Both this blob model and the small-scale heterogeneity model are possible alternatives to active mantle plumes.
\end{abstract}

\section{INTRODUCTION}

The heterogeneity of the earth's mantle is indicated by variations in the ratios of radiogenic isotopes in recent basaltic lavas. At least three end-member components are necessary to explain the isotopic systematics [Zindler et al., 1982]. One component is associated with mid-oceanic ridge lavas and appears to be depleted in volatiles and other incompatible elements. Nd-Sm systematics indicate that mid-oceanic ridge basalts are too depleted to be representative of the average of the whole mantle [e.g., Jacobsen and Wasserburg, 1979; Zindler et al., 1982]. Two more easily melted components are associated with off-axis volcanism. One may be primordial mantle, and the other may be the previously subducted altered oceanic crust. Although the isotopes clearly demonstrate the presence of heterogeneities, they are little help in determining the geometry of the heterogeneities. Thus numerous models for the origin of mantle heterogeneities have been proposed although they generally fall into two types.

\section{Copyright 1984 by the American Geophysical Union.}

Paper number 4B0366.

0148-0227/84/004B-0366\$05.00
In the first type of model the isotopic regions are distinct layers within the earth (Figure 1). The layers may be considered to date from the formation of the earth or to be formed continually through the earth's history. "Hot spot" or "plume" magmas arise from material which has ascended from great depths, perhaps the lower mantle or the core-mantle boundary. The plumes tap both undepleted or primordial mantle and, in some models, volatile enriched zones associated with subducted oceanic crust. Mid-oceanic ridge lavas are associated with material from the upper mantle, which is depleted in the elements which formed the continents.

An alternative to a stratified earth model is the possibility that the heterogeneities are small and ubiquitously distributed throughout the mantle [Davies, 1981; Zindler et al., 1982] (Figure 2). The differences between mid-oceanic ridge basalts and hot spot basalts are attributed to preferential tapping of some heterogeneities with respect to the average mantle during the melting process. At the smaller fractions of melting associated with hot spot basalts, the fraction of melting is much higher in the volatile-rich regions associated with the plume component. The hot spot basalts thus tap a biased sample of the mantle. At the larger percentage of melting associated with mid-oceanic ridge basalts, the fraction of melting does not vary as greatly with volatile con- 


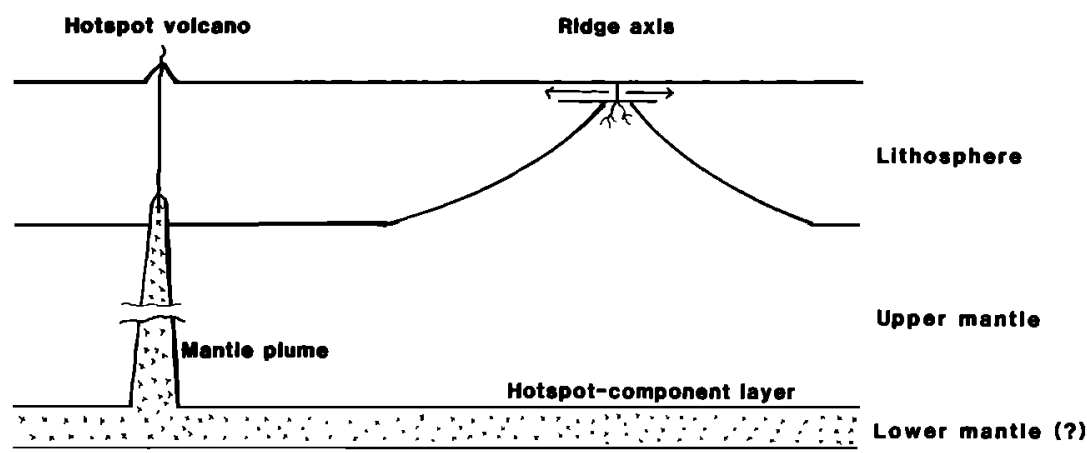

Fig. 1. Schematic diagram showing the origin of hot spot volcanoes according to the mantle plume hypothesis. The upper mantle is homogeneous and is the source region for mid-oceanic ridge basalts. Hot spot volcanoes tap plumes ascending from some layer at depth, probably the lower mantle. The plume is isotopically enriched relative to the upper mantle.

tent. The mid-oceanic ridge lava thus provides a more democratic sample of the mantle.

Situations intermediate between active plumes which tap distinct layers and mantle-wide convection with ubiquitously distributed heterogeneities are certainly conceivable. For example, small-scale heterogeneities and plumes may coexist in the mantle. Alternatively, the circulation in the upper and the lower mantle may be nearly separate, but the lower mantle reservoir is tapped by blobs which become ubiquitously distributed in the upper mantle as small-scale passive heterogeneities (Figure 3).

The presence of ubiquitous heterogeneities in the mantle is a logical consequence of plate tectonics throughout the history of the earth. The oceanic lithosphere is composed of oceanic crust, depleted residuum, and less depleted mantle at greater depths. Hydrothermally altered oceanic crust along with some sediment is probably subducted and later is recycled into mantle-derived magmas [Cohen and O'Nions, 1982; White and Hofmann, 1982; Hofmonn and White, 1982]. The residuum from forming island arc volcanics, and ultimately continents, probably is also returned to the mantle. The initial size of these heterogeneities is small compared with the size of the convection pattern in the mantle. Xenon isotopic variations in mid-oceanic ridge basalts indicate that both degassed and undegassed heterogeneities have persisted from early in the earth's history [Staudacher and Allègre, 1982; Allègre et al., 1983a].

A difficulty with models in which these heterogeneities separate to form layers [e.g., Anderson, 1981; Hofmann and White, 1982; Presnall and Helsley, 1982] is that viscous flow tends to smear out heterogeneities [Richter and Ribe, 1979; Richter et al., 1982]. Another difficulty is that very large density contrasts between small heterogeneities and the "normal" mantle are required for the heterogeneities to separate into layers. For example, the relative rate of movement of a region with respect to its surroundings is by Stokes' law proportional to the density contrast and proportional to the square of the diameter of the region. That is, for a $10-\mathrm{km}$ region to separate from the $100-\mathrm{km}$-thick downgoing slab, the density contrast between the $10-\mathrm{km}$ region and the slab would have to be 100 times the density contrast of the slab with its surroundings.

The physics of melting and the segregation of melt from a heterogeneous source region have not been examined in detail. It is known that the tendency of melt to segregate from a mostly crystalline mush is strongly dependent on the fraction of melt present [Frank, 1968; Sleep, 1974; Turcotte and Ahern, 1978; Basaltic Volcanism Study Project, 1981; Turcotte, 1982]. A small fraction of melt may be retained indefinitely, while melt segregates if more than a few percent melt is present. Segregation of melt at small fractions of partial melting is enhanced by filter pressing if the mush flows through a restricted conduit.

In this paper, the thermal aspects of melting in a heterogeneous source region and the pattern of the flow of magma from the source region at mid-oceanic ridges are examined. It is found that the more volatile-rich heterogeneities are preferentially tapped by off-axis volcanism and that midoceanic ridge lavas should tap material which is more depleted than the average upper mantle.

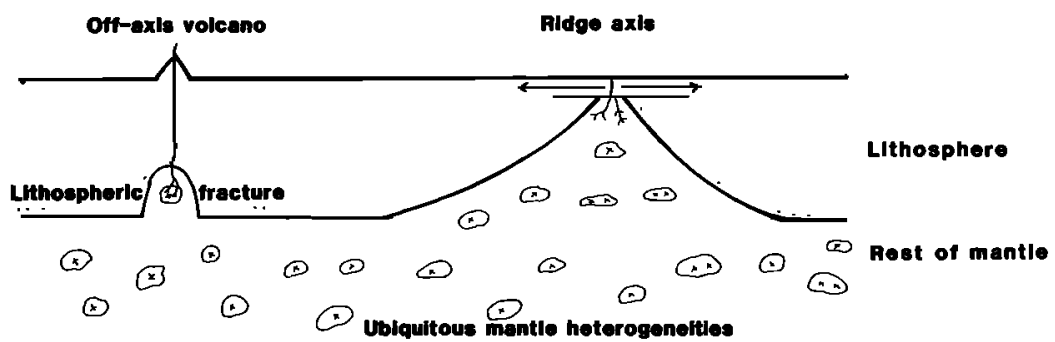

Fig. 2. Schematic diagram showing the origin of isotopically enriched off-axis basalts by biased tapping of magma from ubiquitous small-scale heterogeneities in the source region of the off-axis volcanoes. The source region for midoceanic ridge basalt preferentially taps the more depleted mantle. Off-axis volcanism is related to lithospheric fractures rather than plumes. 

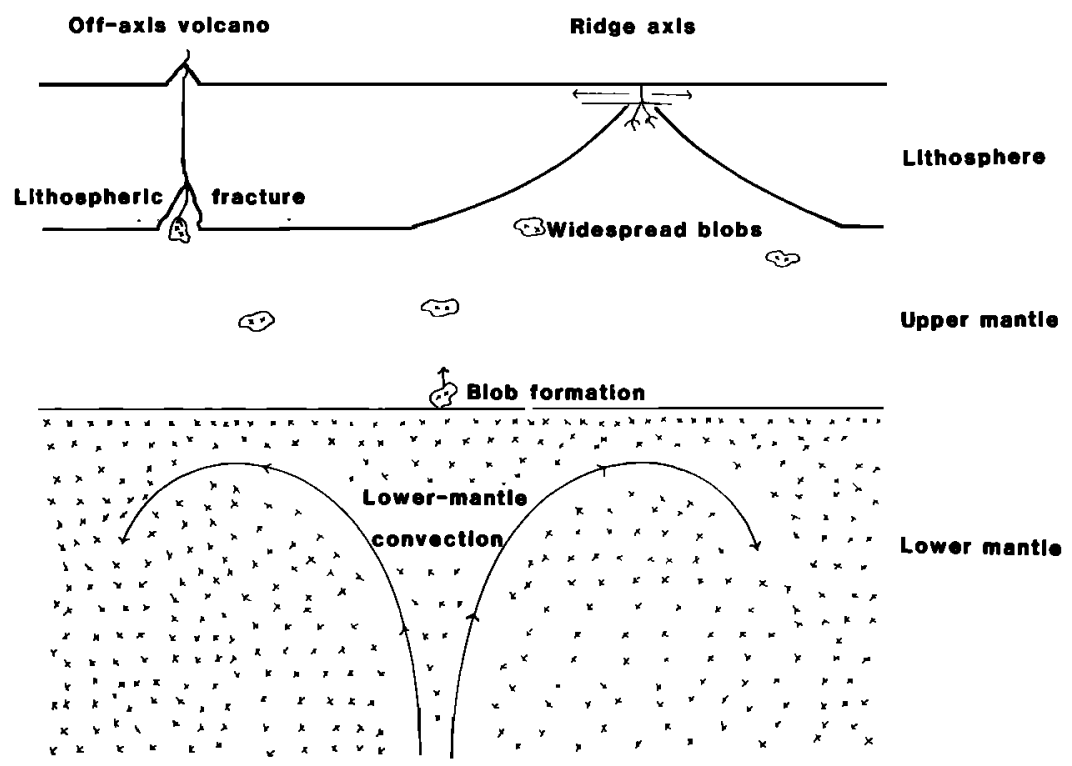

Fig. 3. Schematic diagram showing the origin of isotopically enriched off-axis basalt from blobs originally derived from the lower mantle. Nearly separate convection systems exist in the upper mantle and the lower mantle. Blobs are entrained as passive heterogeneities in the upper mantle and then preferentially tapped by off-axis volcanism.

\section{MELTING AND HEAT TRANSFER}

The essentials of the physics of melting within a heterogeneous region of ascending material, such as beneath a midoceanic ridge or a hot spot volcano, can be visualized as follows. The ascending material is initially solid and melting begins once the adiabat for the material intersects the solidus. Thereafter the fraction of melting gradually increases as the material ascends. The first regions to melt are likely to be volatile rich. The latent heat of melting causes the temperature to increase more slowly (relative to

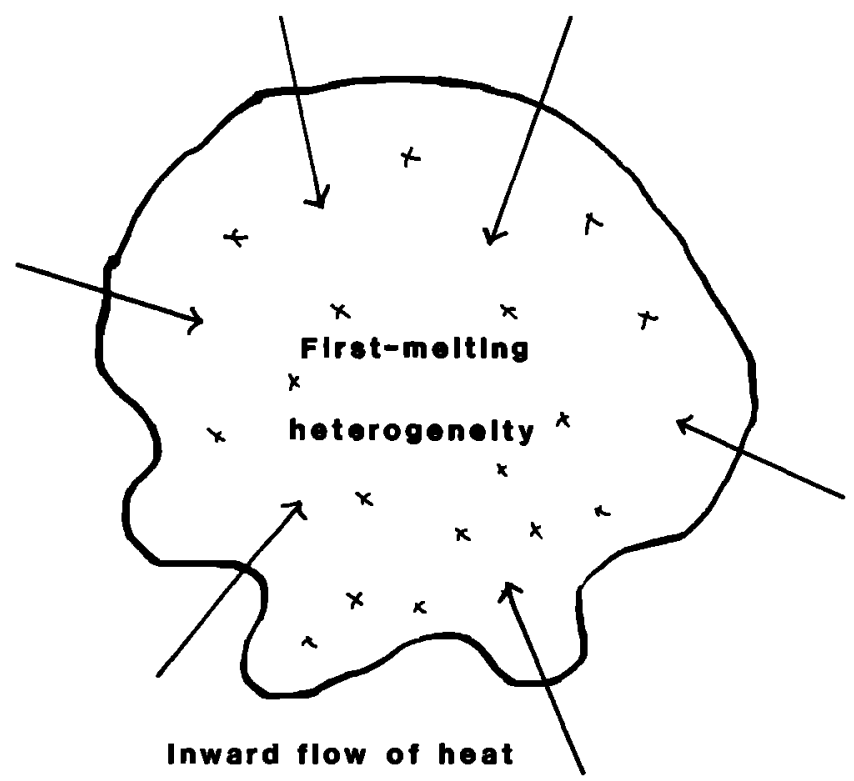

Fig. 4. Schematic diagram showing the first heterogeneity to melt in the source region. The latent heat of melt lowers the temperature in the heterogeneity relative to the surroundings. If the heterogeneity is relative small (less than a few kilometers), significant amounts of heat flow into the heterogeneity and increase the amount of melting. the solidus) in the regions with melting relative to the surrounding regions. Heat thus flows into the first melted regions and increases the amount of melting there (Figure 4). Melting in the last regions to melt is further retarded because heat initially in these regions flows into the surrounding regions. If the heterogeneities are small, the flow of heat among them would be so efficient that the entire region would be isothermal. A small easily melted heterogeneity surrounded by material which does not melt maintains a temperature essentially equal to the dry adiabat of the surrounding material (Figure 5). In contrast, if the heterogene-

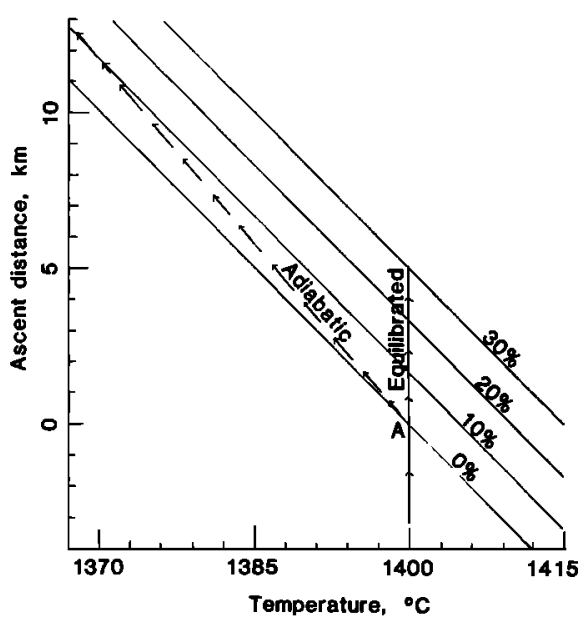

Fig. 5. The fraction of melt in a heterogeneity is shown has a function of vertical ascent distance and temperature. Two limiting models of melting are shown. The ascending region intersects the solidus ( $0 \%$ melt) at point $A$. If the region is adiabatic, then the fraction of melt increases slowly during ascent and the temperature follows a path (dashed line) at a small angle to the solidus. A small thermally equilibrated heterogeneity continues to ascend at the temperature of its more voluminous surroundings (solid line). The fraction of melt in the equilibrated heterogeneity increases rapidly until the low-melting fraction is used up or the surrounding regions begin to melt. 
ities are large, then each heterogeneity would ascend adiabatically. It is obvious that grain-sized heterogeneities are small enough to thermal equilibrate with their surroundings.

A quick analytical estimate of the size range of heterogeneities that remain essentially adiabatic and those which remain isothermal is obtained by noting that

$$
X \approx(x t)^{1 / 2}
$$

where $X$ is the size estimate, $x\left(8 \times 10^{-7}\right) \mathrm{m}^{2} \mathrm{~s}^{-1}$, and $t$ is time. For an upward flow rate of $30 \mathrm{~mm} \mathrm{yr}^{-1}$ which is typical of mid-oceanic ridges, it takes about $1 \mathrm{~m} . y$. for material to traverse the zone of melting. Using these numbers, the size estimate is $5 \mathrm{~km}$. This implies that regions significantly smaller than $5 \mathrm{~km}$ thermally equilibrate with their surroundings while regions significantly larger than $5 \mathrm{~km}$ remain adiabatic. Regions around $5 \mathrm{~km}$ partially thermally equilibrate with their surroundings.

Numerical calculations of heat transfer in a partially molten region are necessary to quantify further the results of the analytical approximation because of latent heat. The calculations are somewhat idealized because the shape, size, and composition of the heterogeneities in the mantle are unknown. I consider both heterogeneities which have a lower melting temperature and heterogeneities which have a greater amount of an easily melted component but the same solidus as their surroundings. Two geometries for the heterogeneities are considered: (1) small isolated spheres with constant but lower melting temperature than there surroundings and (2) tabular regions where the melting temperature varies gradually with position and where the volumes of the easy and hard to melt regions are comparable. The spheres are applicable to the earliest stages of melting, while the tabular heterogeneities are applicable to later stages where melting is much more extensive. In both models, deformation of the heterogeneities during upwelling is ignored, and heat flow is one-dimensional because of the simple geometry. The size range of heterogeneities where melting is essentially isothermal and the difference in the fraction of melting between the equilibrated and the adiabatic cases are of primary interest. Calculations with complexly shaped heterogeneities would obscure the dependence of these features on the physical parameters of the material.

Computations and calculations. The numerical solution of heat flow problems involving partial melting is somewhat complicated because of the latent heat of melting. Following Cawthorn [1975], the heat content of a partially molten region includes both latent heat and specific heat

$$
H=\rho c T+Q f
$$

where $\rho c$ is the volume specific heat $\left(4.2 \mathrm{MW} \mathrm{s} \mathrm{m}^{-3}{ }^{\circ} \mathrm{C}^{-1}\right.$ in the computations), $T$ is the temperature, $Q$ is the latent heat of melting per volume (1260 MW s m${ }^{-3}$ in the computations), and $f$ is the fraction of melt. For simplicity, the specific heat and the latent heat are considered to be constants.

Conductive flow of heat changes the heat content at a point. This heat flow is given by

$$
\mathrm{q}=-x \frac{\partial T}{\partial x}
$$

where $k$ is the thermal conductivity $\left(3.36 \mathrm{~W} \mathrm{~m}^{-1}{ }^{\circ} \mathrm{C}^{-1}\right.$ in the computations), and $x$ is an horizontal coordinate. The rate of change in the heat content at a point is the difference of the heat flow on each side of the point.

$$
\frac{\partial H}{\partial t}=\frac{\partial}{\partial x}\left[-x \frac{\partial T}{\partial x}\right]
$$

where $t$ is time. The third equation for determining the temperature is a relationship between the amount of melting $f$ and the temperature at each point $x$ :

$$
f=f(T, x, z)
$$

where $z$ is the depth.

A linear relationship with depth and temperature is used for (5). The solidus temperature is given by

$$
T_{s}(x)=T_{0}(x)-\left(z_{0}-z\right) \frac{d T_{s}}{d x}
$$

where $T_{0}$ is the solidus temperature at the reference depth $z_{0}$ and $d T_{s} / d z$ is the variation of solidus temperature with depth $\left(3^{\circ} \mathrm{C} \mathrm{km} \mathrm{m}^{-1}\right.$ in the computations). The temperature when partial melt is present is given by

$$
T(x)=\frac{H(x)+Q a(x) T_{s}(x)}{\rho c+Q a(x)}
$$

The parameter $a(x)$ relates the increase of melting at each point to the increase in temperature. (Dimensionally, $a^{-1}$ is the the temperature interval between the liquidus and the solidus if melting is linearly related to temperature; for this paper, the assumption of linearity is justified because only small melt fractions are considered.) Finally, the fraction of melt is

$$
f(x)=\frac{H(x)-\rho c T(x)}{Q}
$$

If a negative fraction of melt is given by this equation, the melt fraction is zero and the temperature is $H(x) / \rho c$.

The fraction of melt in the limiting special cases of adiabatic accent and equilibration of a small heterogeneity with its surroundings were obtained explicitly [Cawthorn, 1975]. For the adiabatic case the fraction of melting is

$$
f_{a d}(x)=\frac{\rho c a(x)\left[T_{0}(x)-T_{s}(x)\right]}{\rho c+Q a(x)}
$$

For the equilibrated heterogeneity the fraction is

$$
f_{e q}(x)=a(x)\left[\mathrm{T}_{0}(\mathrm{x})-\mathrm{T}_{\mathrm{s}}(\mathrm{x})\right]
$$

The maximum amount of melting enhancement is the ration of these two quantities

$$
\Gamma \equiv \frac{f_{e q}}{f_{a d}}=\frac{\rho c+Q a(x)}{\rho c}
$$


The numerical calculation model involves moving with the upwelling material by increments of $1 \mathrm{~km}$. The conductive flow of heat is treated separately from the translation of the material. That is, the material is transferred from one depth to the next and the heat $H(x)$ is kept constant. The temperature and fraction of melt at each point are next computed by solving (6)-(8). The conduction of heat between the grid points is then computed in numerous smaller timesteps. The fraction of melt and the temperature are updated after each of these steps. When enough smaller time steps have been computed to form the time interval between translation steps (the upwelling rate is $30 \mathrm{~mm} \mathrm{yr}^{-1}$ in the computation), the depth is again decreased by one increment and the computation repeated. Numerical accuracy is assured by using sufficiently small time steps.

In the spherical models the solidus temperature within the spherical heterogeneity was assumed to be constant, and no melting occurred outside the spherical heterogeneity. The easily melted sphere was $1.4 \%$ of the total volume, and the parameter $a$ was assumed to be constant, $0.02{ }^{\circ} \mathrm{C}^{-1}$. For these parameters the maximum melt enhancement $\Gamma$ is 7 .

Two idealized relationships were used to define the gradual spatial variation of melting properties in the tabular models. One relationship assumed that the solidus $T_{s}$ varied sinusoidally with position. The increase in the amount of melt with increasing temperature, $a$, was assumed to be constant, $0.02{ }^{\circ} \mathrm{C}^{-1}$. Mathematically, the solidus temperature is given by (6) and

$$
T_{0}(x)=T_{r}+\beta \cos (2 \pi x / X)
$$

where $X$ is the full wavelength of the heterogeneity, $2 \beta$ is the variation in solidus temperature, and $T_{r}$ is a reference temperature. In the calculations the parameter $\beta$ is $25^{\circ} \mathrm{C}$ and the parameter $T_{r}$ is $1425^{\circ} \mathrm{C}$. The material with lowest melting temperature at $x=X / 2$ has a solidus of $1400^{\circ} \mathrm{C}$. The initial temperature of the material at the reference depth $z_{0}$ is also $1400^{\circ} \mathrm{C}$, so that melting begins on the first time step.

The other relationship assumes that the amount of easily melted material varies with position. This possibility is modeled by making the increase of melting with temperature variable while keeping the solidus temperature at the reference depth constant, $1400^{\circ} \mathrm{C}$. Mathematically, this variation is

$$
a(x)=a_{0}-\gamma \cos (2 \pi x / X)
$$

axis but probably at a somewhat shallower level than the where $\gamma$ is the range of variation of the parameter $a$. In the computations, both $a_{0}$ and $\gamma$ are $0.02{ }^{\circ} \mathrm{C}^{-1}$. That is, there is no melting at $x=0$ and $a=0.04{ }^{\circ} \mathrm{C}^{-1}$ at $x=x / 2 X$. This is equivalent to making the difference between the liquidus and the solidus $25^{\circ} \mathrm{C}$ at $x=x / 2 X$.

Computed results. Idealized models were used for melting of a heterogeneous mantle because there is little agreement on even the depth range and temperature of melting of the primary magmas for mid-oceanic ridge basalts [Langmuir et al., 1977; Presnall et al., 1979; cf. Elthon, 1979; Jacques and Green, 1980; Stolper, 1980]. The enhancement of melting in the most easily melted regions should be preserved in more complex formulations of the problem.
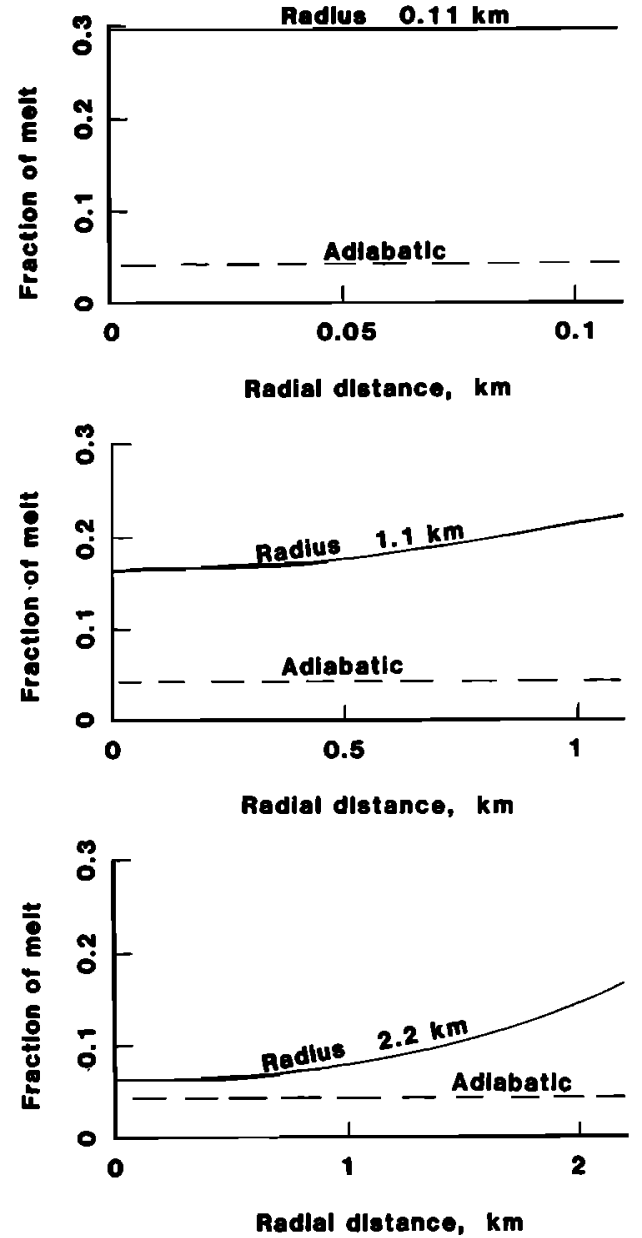

Fig. 6. The fraction of melt within an isolated spherical heterogeneity after $5 \mathrm{~km}$ of ascent is shown. The $0.11-\mathrm{km}$ sphere (top) is thermally equilibrated with its surrounding and the melting within the sphere (solid line) is greatly enhanced over adiabatic melting. The melting in a 1.1-km sphere (middle) and a $2.2-\mathrm{km}$ sphere (bottom) is most enhanced near the edge of the sphere.

The amount of melting for an isolated sphere after $5 \mathrm{~km}$ of ascent is shown in Figure 6. For a radius of $0.11 \mathrm{~km}$ the region including the sphere is isothermal and the melting is enhanced over adiabatic by the maximum factor $\Gamma=7$. The melting in a 1.1-km sphere is more complicated. The amount of melting is highest near the edge of the sphere because heat must flow from the outside into the sphere to enhance melting. That is, a thermal gradient with lower temperatures at the center of the sphere is needed for heat flow. The melting is strongly enhanced throughout this sphere but less than the maximum $\Gamma$. The enhancement of melting in a $2.2-\mathrm{km}$ sphere is mainly on the edge of the sphere. Only a small amount of heat reaches the center of the sphere, and the enhancement of melting is much less there.

The amount of melting in a tabular region with gradually varying solidus after a depth change of $12 \mathrm{~km}$ over a time of $0.4 \mathrm{~m} . y$. is shown in Figure 7. In the model the melting temperature is assumed to vary by $50^{\circ} \mathrm{C}$ across the heterogeneity. For a small heterogeneity with a full wavelength of 2 $\mathrm{km}$ (top), the process is nearly isothermal. The maximum fraction of melting is 0.296 compared with 0.103 for the 


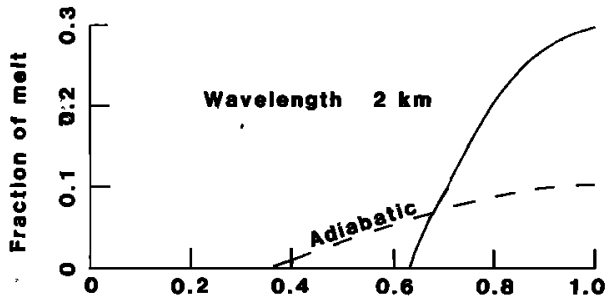

Dlotance acrose heterogenelty, $\mathrm{km}$
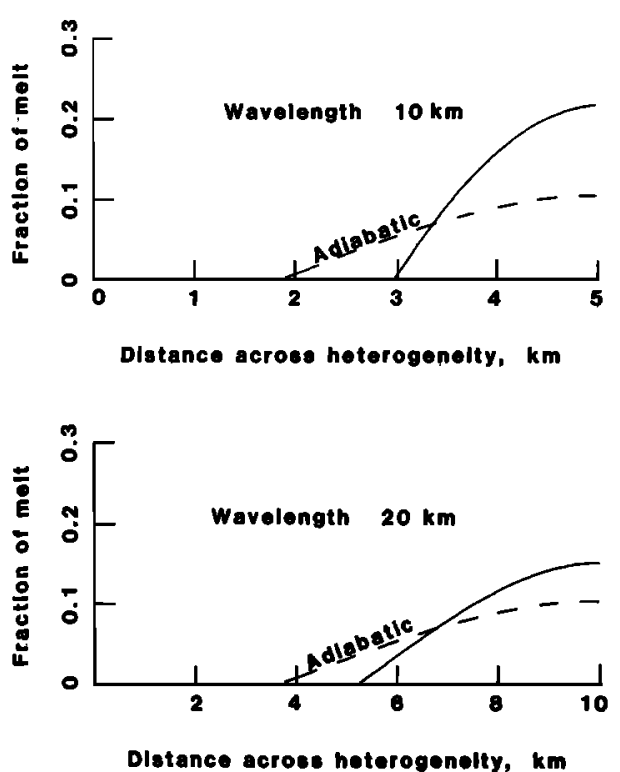

Fig. 7. The fraction of melt present in a region with a gradually varying solidus temperature is shown after $12 \mathrm{~km}$ of ascent. The solidus temperature varies by $50^{\circ} \mathrm{C}$ across the region. The variation of melting temperature is periodic so that the diagrams are symmetric about both end points. For a small heterogeneity (top) the melting is nearly isothermal, and the amount of melting is greatly enhanced at the center of the heterogeneity over the amount of adiabatic melting which would have occurred had there been no lateral flow of heat. For a somewhat larger heterogeneity (middle), enhancement of melting is still significant. For a still larger heterogeneity (bottom) the enhancement of melting is significantly less.

adiabatic case. This enhancement is much less than the maximum factor $\Gamma=7$ because the volumes of the melted, and unmelted regions are comparable rather than the unmelted regions being dominant as in the case of the spheric model. The size of the region which melts is restricted compared with the adiabatic case. For a full wavelength of $10 \mathrm{~km}$ (middle) the maximum fraction of melting is still greatly enhanced over the adiabatic case. For a $20-\mathrm{km}$ full wavelength the fraction of melting is nearer to the adiabatic case.

The difference between adiabatic melting and melting in an isothermally equilibrated region is shown in Figure 8. For the center of the tabular heterogeneity the rate of melting is linear with time in the adiabatic case. The rate of melting decreases slowly with time in the isothermally equilibrated case because more heat can flow into the center of the heterogeneity at first when only a small region is being melted. About 3 times as much melt is produced in the isothermal case as compared with the adiabatic case.

The range of solidus temperature across the tabular het- erogeneity was varied from the $50^{\circ} \mathrm{C}$ used in the previous figures to zero. The enhancement of melting at the center of the heterogeneity is shown in Figure 9. The enhancement for a depth change of $3 \mathrm{~km}$ is significantly greater than the enhancement after a depth change of $12 \mathrm{~km}$ because a much smaller part of the region is molten at first. After a larger part of the region has started to melt, less heat flows from the smaller solid region and is distributed over a larger volume in the partly molten region. Except for very small ranges of melting temperature the enhancement of melting in small heterogeneities is substantial.

The fraction of melting for the tabular model in which the melting temperature is constant but the rate of melting depends on position is shown in Figure 10. The results are qualitatively similar to the results for the model with variable melting temperature in Figure 7. A major difference is that some melt is present everywhere in the model. The fraction of adiabatic melting varies slowly with position on the left side of the figure because the difference between the liquidus and the solidus temperature $1 / a$ is so small that the temperature remains at essentially the solidus temperature and the amount of melting is approximately the difference between the initial temperature and the solidus temperature divided by the factor $Q / \rho c$ (equation' (9)).

As with the previous model, the maximum amount of melting is significantly enhanced for a full wavelength of 2 $\mathrm{km}$ (top) compared with the adiabatic case. The enhancement is slightly less than a factor of 2 . For a full wavelength of $10 \mathrm{~km}$ (bottom) the enhancement of melting is much less. Similar to the isolated spherical model, the greatest enhancement is on the edge rather than the center of the heterogeneity in the $10-\mathrm{km}$ model.

Discussion of models. The main purpose of the computed models is to demonstrate that the amount of melting within an easily melted heterogeneity is greatly increased by the lateral flow of heat. The spherical models are intended to represent the earliest stages of melting, while the tabular models represent intermediate stages where about half of the region is partially molten. In the models, the enhancement was around a factor of 2 or 3 for tabular heterogeneities which have a volume comparable to their surroundings and up to seven for small isolated spheres. Isolated spheres less than a kilometer in radius melt rapidly. Tabular heteroge-

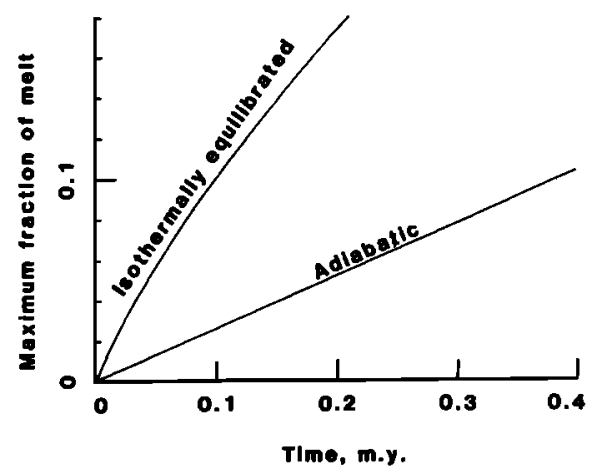

Fig. 8. The increase of the fraction of melt with time for material ascending at $30 \mathrm{~mm} \mathrm{yr}^{-1}$ in the center of an isothermally equilibrated heterogeneity. The fraction of melt increases linearly with time for adiabatic melting. The rate of melting is considerably greater for a very small heterogeneity (which is essentially isothermal), but this rate decreases somewhat with time. 
neities of a few kilometers wavelength are essentially isothermally equilibrated. The size of the heterogeneity which equilibrates isothermally depends on the square root of time or inversely on the square root of the velocity of the upwelling material. A $30 \mathrm{~mm} \mathrm{yr}^{-1}$ velocity was used in the models; therefore the size of heterogeneities which melt isothermally would be somewhat larger at slowly spreading ridges and somewhat smaller for the fastest spreading ridges. The rate of ascent in the source regions of off-axis volcanism is less obvious but is probably slower than that of slowly spreading ridges.

For the enhancement of melting by the lateral flow of heat to affect the composition of the segregated magma, the heterogeneities must exceed some minimum size. Chemical diffusion would isotopically homogenize very small heterogeneities (bread box size). A more relevant limit is that enough melt must form such that veins of melt can accumulate and move some distance to join up with other batches of melt. In order to collect into a pool of magma sufficiently large to migrate by itself to the surface, these heterogeneities must have sufficient size and spatial frequency. A kilometer-sized heterogeneity could produce a large enough magma body on its own.

There is little evidence upon which to speculate on the size of ubiquitous heterogeneities in the mantle as long as only the gross features of isotopic variations are are known. Conceivably, the size of heterogeneities in the mantle may vary regionally because some parts of the mantle may have more complicated strain histories than others. However, if primordial regions still exist in the mantle and contribute a distinct component to magma, then subsequently formed

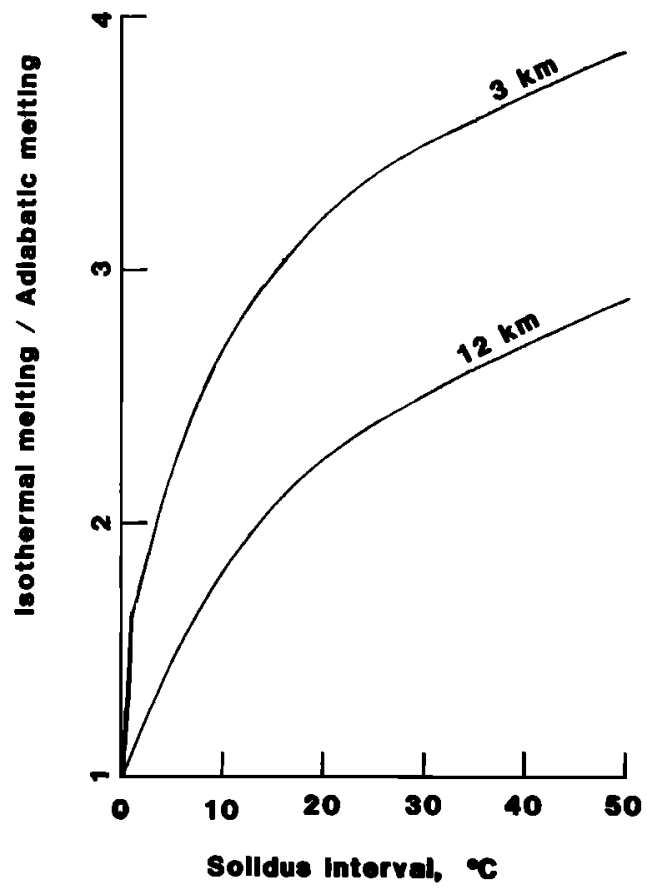

Fig. 9. The ratio of the fraction of melting at the center of the heterogeneity for isothermal melting relative to adiabatic melting is shown for various ranges of the solidus temperature from the center to the outside of the heterogeneity. The enhancement of melting is greater earlier in the melting (after $3 \mathrm{~km}$ of ascent) than later in the melting (after $12 \mathrm{~km}$ of ascent). The enhancement is significant unless the solidus range is quite small $\left(<10^{\circ} \mathrm{C}\right)$.
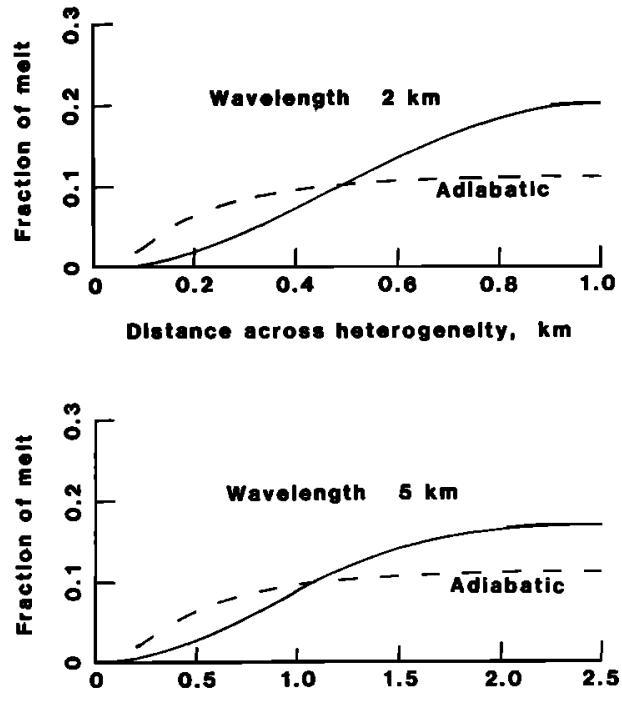

Dlstance across heterogeneity, $\mathrm{km}$

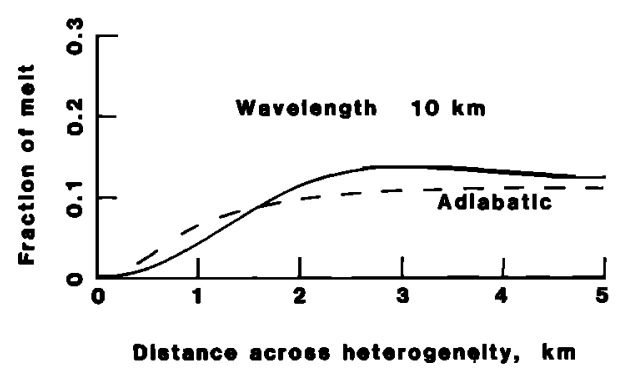

Fig. 10. The range in melt fraction after $12 \mathrm{~km}$ of ascent in the variable melting rate model is plotted as in Figure 7 . The amount of low melting fraction increases to the right, and the solidus is constant. For a small, essentially isothermal heterogeneity (top) the fraction of melting is increased significantly relative to adiabatic melting. A larger heterogeneity (bottom) is nearly adiabatic, and the enhancement of melting is greatest on the flanks of the heterogeneity. An intermediate-size heterogeneity (middle) shows significant enhancement of melting.

regions should also have remained large enough to produce magmas. Any variations in magma composition owing to the size of heterogeneities thus may be quite subtle.

\section{MOVEMENT OF MAGMA TO THE SURFACE}

The hypothesis of ubiquitous heterogeneities in the mantle would be of little relevance if it did not explain at least the gross differences between mid-oceanic ridge basalts and the more enriched off-axis basalts. The hypothesis thus must explain why mid-oceanic ridge basalts are more depleted than average mantle and why some off-axis basalts are more enriched than the average mantle. The previous section provides a possible explanation for the highly enriched off-axis basalts because these rocks form at greater depths where the average fraction of melting is small and where the bulk of the melting and segregation of melt is confined to the more enriched heterogeneities. A good explanation for the depleted character of the mid-oceanic ridge basalts is not immediately evident, however, because it seems that the ridge basalts would always have more than the average amount of easily melted enriched material or at least the average mantle composition. 


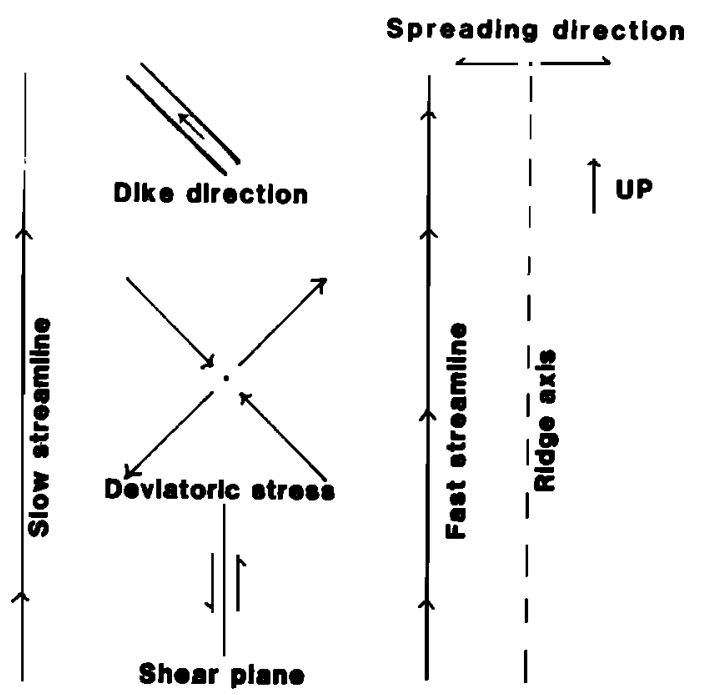

Fig. 11. A schematic cross section of the ridge axis showing the directions of stress and dike propagation. The upward velocity near the axis is vertical and faster than the velocity farther away from the axis. The direction of shearing moves material near the axis up with respect to material farther away from the axis (below). The deviatoric tension is at $45^{\circ}$ up toward the axis (middle). Therefore dikes propagate at $45^{\circ}$ away from the axis so that the earliest material to melt is carried out of the source region.

To explain the depleted character of ridge basalts, it is necessary to consider that melt probably segregates as it forms [Langmuir et al., 1977] and to study the paths taken by batches of magma that segregate at various depths. To do this, we note that magma beneath ridge axes probably moves upward in dikes which grow as cracks in a brittle material [Weertman, 1971]. The direction of propagation is perpendicular to the axis of maximum tension and upward because the melt is less dense than the surrounding rock. The stress field beneath the ridge cannot be computed precisely without explicit consideration of the strains caused by segregation and flow of magma. However, the gross features of the stress field can be easily visualized (Figure 11). The sense of shear strain in the flow is determined by the more rapid rate of upflow near the axis than farther from the axis. The direction of deviatoric tension plunges $45^{\circ}$ away from the axis. Dikes therefore carry magma away from the axis.

The flow pattern at great depths beneath the ridge axis can be represented by the analytical solution for flow driven by motion of the surface plates at a constant velocity away from the ridge axis [Moffatt, 1964]. The uniformly linear viscosity in this solution is intended to model the more complex unknown rheology of the mantle. Body forces are also ignored in the solution. In two-dimensional polar coordinates the velocity of motion is given by

$$
\begin{gathered}
v_{r}=\frac{2}{\pi} \quad U[\theta \sin (\theta)-\cos (\theta)] \\
v_{\theta}=\frac{2}{\pi} \quad U \theta \cos (\theta)
\end{gathered}
$$

where $r$ is the distance from the surface at the ridge axis, $\theta$ is the angle measured from the vertical at the ridge axis, and
$U$ is the half spreading rate (Figure 12). The velocity of upwelling at $\theta=0$ is $2 U / \pi$ or about $70 \%$ of the half spreading rate.

The principle axes of stress are aligned at $45^{\circ}$ from the radial direction. This can be seen since

$$
\sigma_{r r}=\eta \frac{\partial v_{r}}{\partial r}=0
$$

and

$$
\sigma_{\theta \theta}=\frac{\eta}{r}\left[\frac{\partial v_{\theta}}{\partial \theta}+v_{r}\right]=0
$$

where $\sigma$ is the stress tensor and $\eta$ is the viscosity of the rock. The magnitude of the deviatoric stress is proportional to $\sin (\theta)$. The deviatoric stress is zero directly beneath the ridge axis. Within the upwelling, the sense of shear is such that the axis of maximum tension points upward toward the axis and downward away from the axis. Dikes of melt, therefore, propagate upward and away from the axis. At $\theta= \pm 45^{\circ}$ the axis of maximum tension is horizontal, and the direction of dike propagation is vertical. In the upper octants of the region $|\theta|>45^{\circ}$ the direction of dike propagation is inward toward the axis. Mathematically, the melt trajectories are given by

$$
\ln \left[\frac{r_{0}}{r}\right]=\theta
$$

where $r_{0}$ is the value of $r$ at $\theta=0$ for a particular trajectory. Although the model is highly idealized, identical melt trajectories are obtained within a narrow wedge-shaped conduit or if the viscosity varies with $r$ [Lachenbruch and Nathenson, 1976]. Mathematically, this is whenever velocity boundary conditions are independent of $r$ or equivalently the problem is self-similar. Only a qualitative discussion of the factors which cause the actual stress orientation to differ

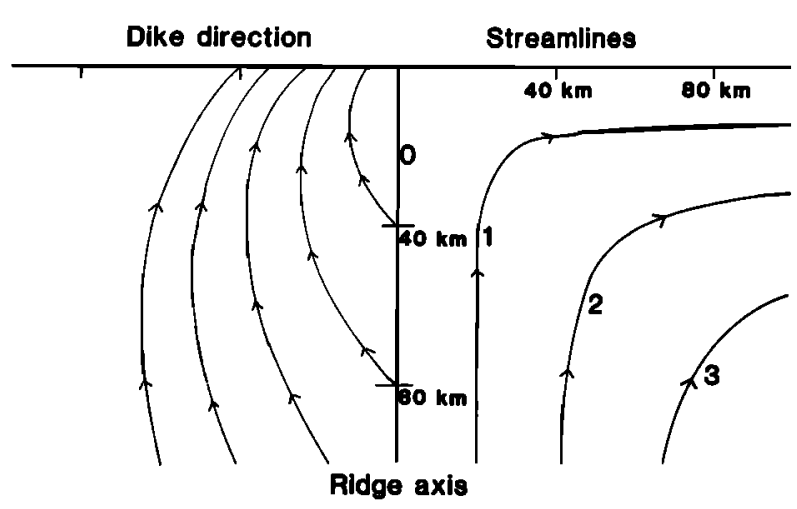

Fig. 12. Streamlines (right) and the trajectories of dike propagation (left) are shown for the analytic solution for flow at the ridge axis. This solution is probably closer to the actual flow pattern at greater depths. Note that dikes in the upwelling region near the axis propagate away from the axis. Streamlines are arbitrarily numbered $0-4$ with 0 being the ridge axis and the surface. An equal volume of flow occurs within each region demarcated by the streamlines so that the velocity is inversely proportional to the spacing of the streamlines. A scale is given to indicate the depths for which the solution is intended to be applicable. 
Fast rldge

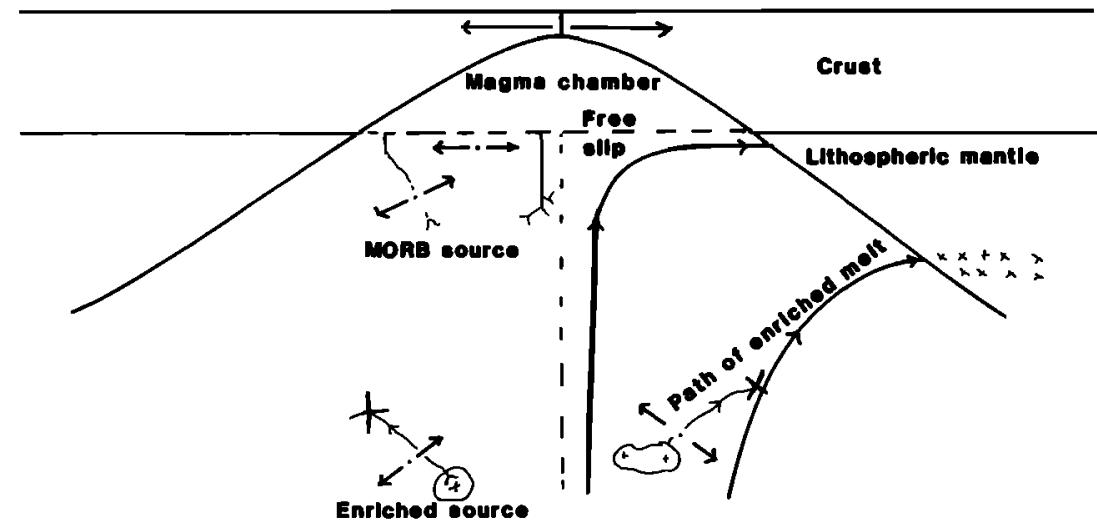

Fig. 13. A schematic diagram showing the fate of early and late formed melt at a fast ridge. The early melt from an enriched heterogeneity propagates as a dike for a distance away from the upwelling and is finally intruded into the upwelling mantle at the two points marked with a large cross. The enriched material is then passively carried in the flow along the streamline shown on the right and eventually forms an enriched layer in the lithosphere crosses. The crustal magma chamber acts as a free slip boundary and also to trap and mixed melts from various parts of the MORB source region. The directions of deviatoric tension are indicated by paired arrows.

from the analytical model and effect dike propagation is attempted below.

The assumptions of the analytical solution are most applicable at the great depth where the initial melting of enriched heterogeneities occurs (Figure 12). When these heterogeneities segregate melt, the dikes would propagate away from the ridge axis and thus escape eruption at the ridge axis. The remaining material would be depleted relative to average mantle and form mid-oceanic ridge basalts when further extensive melting occurs at higher levels. For this mechanism to effect significantly the chemistry of the source region at ridges, the upwelling mantle must be able to fracture brittly, and the fractures must propagate far enough to carry the first melt out of the central region of upwelling but not all the way to the surface (where enriched lavas are not usually observed). The first problem can be answered with some confidence because syntectonic (brittle) dikes, cracks, and veins are common in rocks which have undergone ductile deformation. The most relevant rock bodies for the present purpose are deformed dunite, pyroxenite, and gabbro dikes in the (mantle) harzburgite tectonite of the Oman ophiolite [Boudier and Coleman, 1981]. These bodies cut the harzburgite while it was flowing beneath a ridge axis but probably at a somewhat shallower level than the trajectories shown in the figure. The propagation distance of dikes is more difficult to predict, as it depends more on the volume in the initial melt body and on the details of rheology. The observations of Boudier and Coleman [1981] indicate that at least some material in dikes does not reach the surface at ridges and that the dikes move at least some distance from their source.

Three factors make the directions of stresses at shallower depths where ridge basalts form different from the directions predicted by the analytical model. First, the horizontal velocity of the surface plate does not attain the spreading velocity exactly at the ridge axis (mathematically, this causes the boundary condition to depend on $r$ and thus not be self-similar). Second, the flow field near the surface is modified by the large volumes of melt which segregate and flow to the surface. Third, the viscosity of the material under the ridge axis is not constant with position. In particular, the lithosphere may retard the escape of off-axis magma. The first of these effects is most easily visualized and considered below in more detail.

Consider first a fast-spreading ridge with a significant axial magma chamber (Figure 13). For the flow in the more viscous underlying mantle, the magma chamber acts as a freely slipping boundary. The principle axis of tension is thus horizontal beneath the boundary and the direction of dike propagation vertical. At a moderate depth beneath the chamber, horizontal shear stress results from the faster moving material at depth dragging the shallower material beneath the magma chamber. This sense of shear has been inferred from the Oman ophiolite [Boudier and Coleman, 1981]. The direction of dike propagation is thus somewhat outward from the ridge axis.

For a slow-spreading ridge, no significant magma chamber is present (Figure 14). Significant amounts of earlier formed melt move away from the axis and miss the crustal magma chamber as they ascend. Slightly off-axial magma at a slow ridge thus should be expected to show lower degrees of partial melting and a somewhat greater source depth than axial magma. This trend is well exhibited in the FAMOUS area on the Mid-Atlantic Ridge for the basalt samples which Langmuir et al. [1977] used to infer that melt segregates as it forms. The chemical variations occur over a few kilometers across the axial zone and are not accompanied by $\mathrm{Nd}$ and $\mathrm{Sr}$ isotopic variations [White, 1979].

A complication that makes quantification of the above effect difficult is that the region where the lateral velocity increases to the spreading rate is controlled by the width of the intrusion zone and the tectonics of the central rift. The sense of shear beneath the lithosphere is the opposite of the sense of shear in the previous case of fast ridges because the underlying mantle is dragged by the lithosphere. This would tend to deflect dikes somewhat toward the axis at shallow depths. At greater depths, dikes are deflected away from the axis and thus should miss the crustal magma chamber.

Segregation and tapping of large volumes of partial melt 


\section{Slow ridge}

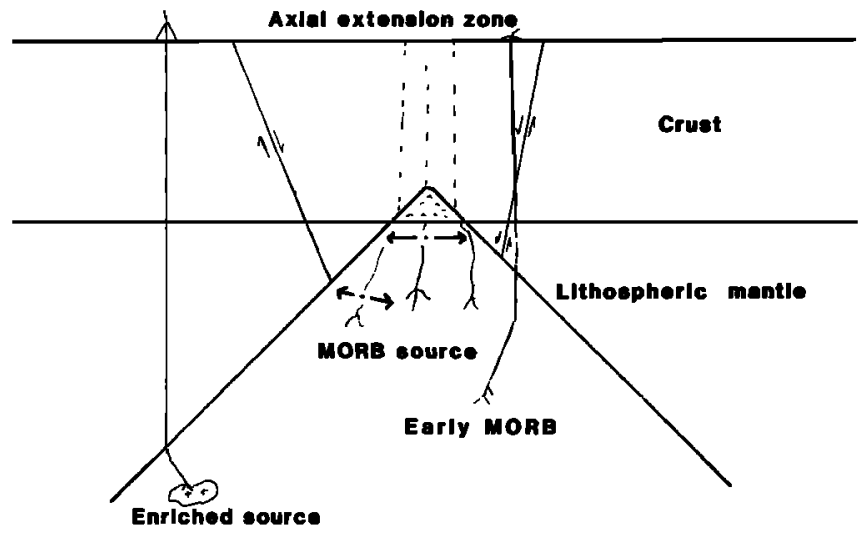

Fig. 14. A schematic diagram shows the fate of early and late formed melt at a slow ridge. Some melt from enriched heterogeneities may propagate as dikes through the lithosphere and then feed near-axis volcanoes (if the stresses are right to form cracks in the lithosphere). The axial source region is somewhat deeper than at fast ridges because dikes at intermediate depths in the mantle are deflected toward the axis. The magma chamber is small or even transient. Some mantle-derived batches of melt may miss the chamber and erupt at the surface at the edge of the axial zone. These magmas have lower degrees of partial melting and somewhat greater source depth than the MORB erupted right at the axis.

probably creates its own pressure gradient. That is, melt has some tendency to flow toward the zone of active melt segregation, especially if a large volume of melt is being generated. As melt segregation should be more rapid near the center of the upwelling region, melt is brought back toward the ridge axis. This effect is difficult to quantify but should be important only at the shallower depths where mid-oceanic ridge basalts are generated.

The segregation of melt and, at slow ridges, the conduction of heat increases the viscosity of material upwelling away from the ridge axis. The zone of upwelling is thus narrower than predicted by the analytical model, especially at shallower depth. The stress directions given by the model hold within the active part of the conduit as noted above, but the stress field in the more viscous material on the sides of the active conduit is probably close to horizontal extension and the direction of dike propagation is close to vertical.

\section{DISCUSSION AND PETROLOGY}

The small ubiquitous heterogeneity model may reduce or obviate the need for mantle plumes which ascend from some layer in the mantle, as recently noted by Davies [1981], Zindler et al. [1982], and Richardson et al. [1982]. Geophysical alternatives to mantle plumes usually consider that hot spot volcanic chains are associated with cracks in the mantle rather than plumes [Sleep, 1974; Turcotte and Oxburgh, 1973, 1976; Solomon and Sleep, 1974]. These alternatives have been difficult to test because the intraplate stress which is believed to cause the cracks is as poorly determined as the flow pattern in the mantle believed to cause the plumes themselves. The stress hypothesis may be somewhat more testable because the stresses within the plates can be directly measured [Zoback and Zoback, 1980] while the flow in the deep mantle cannot.
The main argument for stress-induced cracks rather than plumes is thus circumstantial. Although plumes are an excellent geometrical explanation for well-defined hot spots, such as Hawaii, some hot spots are actually "hot lines", which is what would be expected from cracks [Bonatti et al., 1977; Pilger, 1982]. Extensive replacement of the lower lithosphere by asthenosphere is associated with mid-plate hot spots [Crough, 1978; Von Herzen et al., 1982]. This replacement implies failure of at least the lower lithosphere and hence is compatible with cracks as well as plumes. Small near-axis seamounts appear to be controlled by cracks associated with fracture zones [Batiza and Vanko, 1983] Another argument is that off-axis volcanism is widely distributed in the oceanic plates and the small centers of volcanism are not distinctive from the larger centers attributed to hot spots [Fujita and Sleep, 1978; Batiza, 1982; Batiza and Vanko, 1983, 1984]. All off-axis volcanism is seldom attributed to plumes because a very large number of mantle plumes of varying size and composition (including some indistinguishable from mid-ocean ridge basalt) are required. That is, if a continuum exists between Hawaiian-type hot spots and minor off-axis volcanoes, then it is reasonable to attribute both to the same mechanism: cracks.

The application of the model for melt segregation to petrology contains little new except for a plausible explanation for the depletion of the ridge volcanics. This depletion comes both from biased tapping of late melting regions, which were depleted much earlier in the earth's history, and from the loss of the first melt from much of the source region beneath the ridge. The second effect would cause mid-oceanic ridge basalts to be more depleted in highly incompatible elements, which are used up by the first melt, than moderately incompatible elements, as is observed [Hofmann, 1983]. The gross features of the model do not depend on petrological details but only that small-scale heterogeneities exist and that the melting behavior of the heterogeneities correlates with isotopic composition. In particular, the general features of melting behavior and melt migration do not depend on the precise depth of the generation of the basaltic magma at mid-oceanic ridges.

Local scatter in isotopic values at ridges. The ubiquitous heterogeneity model, with or without blobs, provides a viable theory for the local scatter in isotope values along the ridge axis [Duprè and Allegre, 1983; Allegre et al., 1983b; Batiza, 1984]. The scatter is less at fast-spreading ridges because large magma chambers are present and many mantle-derived batches of magma mix in the chamber to give a mean isotopic composition to volcanic rocks derived from the chamber. Magma chambers are transient and narrow at slow ridges, and single batches of magma can erupt with little mixing and thus show great isotopic scatter. That is, the most depleted as well as the most enriched isotopic ratios are expected at slow ridges. At intermediate spreading rates, both mixing and scatter are apparent [Clague et al., 1983; Eaby et al., 1984].

Isotopic scatter is most pronounced on the southwest Indian ridge, which is the slowest spreading part of the mid-oceanic ridge system [LeRoex et al., 1983]. The full range in isotopic values observed worldwide at ridges is found at most localities along the ridge. There appears to be little trend in either the amount of scatter or the mean value along the ridge.

Regional isotopic variations on ridges. Regional varia- 
tions of isotopic ratios along mid-oceanic ridge axes are well documented on the Galapagos Spreading Ridge [Verma and Schilling, 1982] and the Mid-Atlantic Ridge [White and Schilling, 1978; Schilling et al., 1983] but not evident on the Juan de Fuca Ridge [Eaby et al., 1984] or the southwest Indian ridge [LeRoex et al., 1983]. A plume or blob model provides an immediate but not very satisfying explanation: there are simply more plumes or blobs in some places on the ridge than others. (The best physical model for tapping of plumes and blobs from the lower mantle [Olson, 1983] has not yet been developed to the point where it is possible to predict the distribution of plumes.) The regional isotopic anomalies appear to be the most difficult feature to explain by ubiquitous mantle heterogeneities.

Regional isotopic variations are not unexpected in ubiquitous small-scale heterogeneities as factors which may effect the tapping of melt including the spreading rate, the obliquity of the ridge, the presence of leakly transform faults and bifurcations, and the intraplate stress field (which controls cracks) all vary regionally along a ridge axis. A quantitative theory for these mechanisms may be as difficult to formulate as one for plume ascent, but empirical relationships among these features (which except for stress are easily observed), isotopic and chemical variations, and crustal thicknesses (which give the total amount of magma tapped) can be appraised. The absence of such correlations would be reason for invoking a separate blob or plume source. A strong empirical relationship would be evidence that the regional isotopic trends are the result of systematic variations in the tapping of magma from ubiquitously small-scale heterogeneities in the mantle.

Off-axis volcanism. Near-axis seamounts tap depths in the mantle similar to ridges and hence erupt magmas similar to mid-oceanic ridge basalts [Batiza, 1982; Batiza and Vanko, 1984]. (The minimum source depth for seamounts is crudely the thickness of the thermal lithosphere: $12 \mathrm{~km}$ for $1 \mathrm{~m} . \mathrm{y}$. crust and $24 \mathrm{~km}$ for $4 \mathrm{~m}$.y. crust.) In analogy with slow ridges, batches of magma escape mixing and give rise to scatter in isotopic values. Near-axis seamounts sometimes tap the enriched material which moved laterally away from the ridge axis. Another effect noted by Duprè and Allegre [1983] and Allegre et al. [1983b] is that off-axial melt may feed back into the ridge axis along leakly transform faults (or cracks related to near-axis sea mounts).

The environment of magma generation far away from the ridge axis is more complicated because of the stratification of the lithosphere produced by the generation of melt at the ridge axis. The uppermost part of the mantle is probably a depleted residuum which cannot generate additional basaltic melt. At somewhat greater depths the rocks are capable of generating some magma, either from melt which was retained in the source region or from heterogeneities which did not melt at the ridge axis. The importance of small fractions of melting in regions with low ${ }^{87} \mathrm{Sr} /{ }^{86} \mathrm{Sr}$ to the generation of Hawaiian basalts has been discussed by Chen and Frey [1983]. Below this depth there would be a region which was enriched in the initially melted components which moved out to the side at the ridge axis. This material would contain more of the plume component than the average mantle. The process for generating this enriched layer is basically the introduction of small volumes of melt or the mantle metasomatism hypothesis discussed by Richardson et al. [1982] for basalts on the aseismic Walvis ridge. Below the depth of enrichment, the mantle would approach its average composition.

Global mass balance. The significant difficulty with mantle-wide convention and only small-scale heterogeneities is the relative masses of the different reservoirs. This can be illustrated by the $\mathrm{Nd}-\mathrm{Pb}$ and $\mathrm{Sr}-\mathrm{Pb}$ plots of Zindler et al. [1982], where it is evident that the plume component contributes a subordinate amount of $\mathrm{Nd}, \mathrm{Sr}$, and $\mathrm{Pb}$ to many of the off-axis basalts in that study and all of the ridge basalts. There is a large gap on the plots between the localities enriched in the plume component and all the other localities. The efficient exclusion of the plume component from all but a few source regions can be explained if the component is isolated within physical heterogeneities rather than being present in variable amounts in each source region. That is, the heterogeneities containing the plume component melt before the rest of the mantle and, even at off-axis volcanoes, the magma moves laterally before the more depleted magma which reaches the surface segregates. Conversely, the plume component sometimes forms the bulk of a magma because it may melt and segregate at locations where the more difficult to melt components are still solid. (The continuum between the MORB component and the third component on Zindler et al.'s [1982] diagrams indicates that these components may be intermixed endmembers rather than physically separate heterogeneities. The third component apparently melts before the MORB and thus is enriched in off-axis magmas where the potential source regions for the MORB component are not yet molten. Presumably, the third component moves laterally away from the shallower zone where mid-oceanic ridge basalts are generated.)

For the plume component to be so efficiently excluded from so many source regions in the postulated manner, it must be a subordinate fraction of the mantle source region. If mass balances require the plume component to make up the bulk of the mantle, this component must be largely isolated from the upper mantle and introduced in small quantities as plumes or blobs. (See Davies [1981] for a view that the plume component may be a subordinate fraction and, for example, Jacobsen and Wasserburg [1979] and DePaolo [1980] for the more prevalent view that the plume component makes up around $50 \%$ of the whole mantle, and Zindler et al. [1982] for an intermediate viewpoint.) A model involving widely distributed blobs [Duprè and Allègre, 1983; Allègre et al., 1983b] avoids this mass balance problem but retains the other mechanical aspects of the ubiquitous heterogeneity model. Conceivably, these blobs may remain as "passive" heterogeneities in the upper mantle for a long time before entering the source regions of magmas, rather than directly ascending as plumes (Figure 3). In particular, the thermal and mechanical arguments on the tapping of melt from small-scale heterogeneities apply whether the heterogeneities originated as blobs or by the whole mantle convection and plate tectonics. The evidence for mechanical plumes, therefore, must be appraised separately from mass balance evidence that distinguishes both plumes and blobs from mantle-wide ubiquitous heterogeneities.

Acknowledgments. I thank David Clague and Janet Morton for critically reading this paper. I also thank Jackie Eaby, William White, and Rodey Batiza for helpful discussions. Bruce Marsh reviewed the manuscript. Rodey Batiza, David Vanko, Jackie 
Eaby, David Clague, and John Delaney furnished preprints of their papers. The presentations at the session on mantle heterogeneities at the spring 1983 AGU meeting were helpful in formulating the concepts presented in this paper. The research was supported in part by the National Science Foundation grant EAR81-15522 and grant EAR 83-12935.

\section{REFERENCES}

Allègre, C. J., T. Staudacher, P. Sarda, and M. Kurz, Constraints on evolution of the earth's mantle from rare gas systematics, Nature, 303, 762-766, 1983 a.

Allègre, C. J., B. Duprè, and B. Hamelin, Geochemistry of oceanic ridge basalts explained by blob mantle mixing, Eos Trans. $A G U$, $64,324,1983 b$.

Anderson, D. L., Hotspots, basalts, and the evolution of the mantle, Science, 213, 82-89, 1981.

Basaltic Volcanism Study Project, Basaltic Volcanism on the Terrestrial Planets, 1286 pp., Pergamon, New York, 1981.

Batiza, R., Abundances, distribution and sizes of volcanoes in the Pacific Ocean and implications for the origin of non-hotspot volcanoes, Earth. Planet. Sci. Lett., 60, 195-206, 1982.

Batiza, R., Inverse relationship between $\mathrm{Sr}$ isotope diversity and rate of oceanic volcanism has implication for mantle heterogeneity, Nature, 309, 440-441, 1984.

Batiza, R., and D. Vanko, Volcanic development of small oceanic central volcanoes on the flanks of the East Pacific Rise inferred from narrow beam echo sounder surveys, Mar. Geol., 54, 53-90, 1983.

Batiza, R., and D. Vanko, Petrology of young Pacific seamounts, $J$. Geophys. Res., in press, 1984.

Bonatti, E., C. G. A. Harrison, D. E. Fisher, J. Honnorez, J. G. Schilling, J. J. Stipp, and M. Zentelli, Easter volcanic chain (southeast Pacific): A mantle hot line, J. Geophys. Res., 82, 2457-2478, 1977.

Boudier, F., and R. G. Coleman, Cross section through the peridotite in the Samail ophiolite, southeastern Oman, J. Geophys. Res., 86, 2573-2592, 1981.

Cawthorn, R. G., Degrees of melting in mantle diapirs and the origin of ultrabasic liquids, Earth Planet. Sci. Lett., 27, 113-120, 1975.

Chen, C.-Y., and F. A. Frey, Origin of Hawaiian tholeiite and alkali basalt, Nature, 302, 785-789, 1983.

Clague, D., J. S. Eaby, and J. R. Delaney, Petrological evidence for long-lived axial magma chambers on the Juan de Fuca Ridge (abstract), in Fifth Annual Geodynamics Research Symposium on Oceanic Lithosphere: Origin, Structure, and Dynamics, Texas A \& M University, College Station, 1983.

Cohen, R. S., and R. K. O'Nions, Identification of recycled continental material in the mantle from $\mathrm{Sr}, \mathrm{Nd}$, and $\mathrm{Pb}$ isotope investigations, Earth Planet. Sci. Lett., 61, 73-84, 1982.

Crough, S. T., Thermal origin of hot-spot swells, Geophys. J. R. Astron. Soc., 55, 451--469, 1978.

Davies, G. F., Earth's neodymium budget and structure and evolution of the mantle, Nature, 290, 208-213, 1981.

DePaolo, D. J., Crustal growth and mantle evolution: Inferences from models of element transport and $\mathrm{Nd}$ and $\mathrm{Sr}$ isotopes, Geochim. Cosmochim. Acta, 44, 1185-1196, 1980.

Duprè, B., and $\mathrm{C}$. J. Allègre, $\mathrm{Pb}-\mathrm{Sr}$ isotope variations in Indian Ocean basalts and mixing phenomena, Nature, 303, 142-146, 1983.

Eaby, J., D. A. Clague, and J. R. Delaney, Sr-isotopic variations along the Juan de Fuca Ridge, J. Geophys. Res., in press, 1984.

Elthon, D., High magnesia liquids as the parental magma for ocean floor basalts, Nature, 278, 514-518, 1979.

Frank, F. C., Two-component flow and convection in the earth's upper mantle, Nature, 220, 350-352, 1968.

Fujita, K., and N. H. Sleep, Membrane stresses near mid-ocean ridge transform intersections, Tectonophysics, 50, 207-221, 1978.

Hofmann, A. W., Buffered and unbuffered elements in MORB (abstract), Eos Trans. AGU, 64, 345, 1983.

Hofmann, A. W., and W. M. White, Mantle plumes from ancient oceanic crust, Earth Planet. Sci. Lett., 57, 421-436, 1982.

Jacobsen, S. B., and G. J. Wasserburg, The mean age of mantle and crustal reservoirs, J. Geophys. Res., 84, 7411-7428, 1979.
Jacques, A., and D. H. Green, Anhydrous melting of peridotite at $0-15 \mathrm{~kb}$ pressure and the genesis of tholeitic basalt, Contrib. Mineral. Petrol., 73, 287-310, 1980.

Lachenbruch, A. H., and M. Nathenson, Rise of a variableviscosity fluid in a steadily spreading wedge shaped conduit with accreting walls, J. Res. U. S. Geol. Surv., 4, 181-188, 1976.

Langmuir, C. H., J. F. Bender, A. E. Bence, G. N. Hanson, and S. R. Taylor, Petrogensis of basalts from the FAMOUS area, Mid-Atlantic Ridge, Earth Planet. Sci. Lett., 36, 133-156, 1977.

LeRoex, A. P., H. J. B. Dick, A. J. Erlank, A. M. Reid, F. A. Frey, and S. R. Hart, Geochemistry, mineralogy and petrogenesis of lavas erupted along the southwest Indian ridge between the Bouvet triple junction and 11 degrees east, $J$. Petrol., 24, 267$318,1983$.

Moffatt, H. K., Viscous and resistive eddies near a sharp corner, $J$. Fluid Mech., 18, 1-18, 1964.

Olson, P., An experimental approach to thermal convection in a two-layer mantle (abstract), Eos Trans. AGU, 64, 325, 1983.

Pilger, R. H., The origin of hotspot traces: Evidence from eastern Australia, J. Geophys. Res, 87, 1825-1834, 1982.

Presnall, D. C., and C. E. Helsley, Diapirism of depleted peridotite-A model for the origin of hot spots, Phys. Earth Planet. Inter., 29, 148-160, 1982.

Presnall, D. C., J. R. Dixon, T. H. O'Donnell, and S. A. Dixon, Generation of mid-ocean ridge tholeiites, J. Petrol., 20, 3-36, 1979.

Richardson, S. H., A. J. Erlank, A. R. Duncan, and D. L. Reid, Correlated $\mathrm{Nd}, \mathrm{Sr}$, and $\mathrm{Pb}$ isotope variation in Walvis Ridge basalts and implications for the evolution of their mantle source, Earth Planet. Sci. Lett., 59, 327-342, 1982.

Richter, F. M., and N. M. Ribe, Importance of advection in determining the local isotopic composition of the mantle, Earth Planet. Sci. Lett., 43, 212-222, 1979.

Richter, F. M., S. F. Daly, and H.-C. Nataf, A parameterized model for the evolution of isotopic heterogeneities in a convecting system, Earth Planet. Sci. Lett., 60, 178-194, 1982.

Schilling, J.-G., M. Zajac, R. Evans, T. Johnston, W. White, J. D. Devine, and R. Kingsley, Petrologic and geochemical variations along the Mid-Atlantic ridge from $29^{\circ} \mathrm{N}$ to $73^{\circ} \mathrm{N}, A m$. J. Sci., 283, 510-586, 1983.

Sleep, N. H., Segregation of magma from a mostly crystalline mush, Geol. Soc. Am. Bull., 85, 1225-1232, 1974.

Solomon, S. C., and N. H. Sleep, Some models for absolute plate motions, J. Geophys. Res., 79, 2537-2567, 1974.

Staudacher, T., and C. J. Allégre, Terrestrial xenonology, Earth Planet. Sci. Lett., 60, 389-406, 1982.

Stolper, E., A phase diagram for mid-ocean ridge basalts: Preliminary results and implications, Contrib. Mineral. Petrol., 74, 13$28,1980$.

Turcotte, D. L., Magma migration, Annu. Rev. Earth. Planet. Sci., 10, 397-408, 1982.

Turcotte, D. L., and J. L. Ahern, Magma production and migration within the moon, Proc. Lunar Sci. Conf., 9th, 307-318, 1978.

Turcotte, D. L., and E. R. Oxburgh, Mid-plate tectonics, Nature, 244, 337-339, 1973.

Turcotte, D. L., and E. R. Oxburgh, Stress accumulation in the lithosphere, Tectonophysics, 35, 183-199, 1976.

Verma, S. P., and J.-G. Schilling, Galapagos hot spot-spreading center system, $2,{ }^{87} \mathrm{Sr} /{ }^{86} \mathrm{Sr}$ and large ion lithophile element variations $\left(85^{\circ} \mathrm{W}-101^{\circ} \mathrm{W}\right), \mathrm{J}$. Geophys. Res., 87, 10838-10856, 1982.

Von Herzen, R. P., R. S. Detrick, S. T. Crough, D. Epp, and U. Fehn, Thermal origin of the Hawaiian swell: Heat flow evidence and thermal models, J. Geophys. Res., 87, 6711-6723, 1982.

Weertman, J., Theory of water-filled crevasses in glaciers applied to vertical magma transport beneath oceanic ridges, J. Geophys. Res., 76, 1171-1183, 1971.

White, W. H., Geochemistry of Basalts from the FAMOUS area: A reexamination, Year book Carnegie Inst. Washington, 78, 325$331,1979$.

White, W. H., and A. W. Hofmann, Sr and Nd isotope geochemistry of oceanic basalts and mantle evolution, Nature, 296, 821825, 1982.

White, W. M., and J. G. Schilling, The nature and origin of geochemical variations in Mid-Atlantic Ridge basalts from the cen- 
tral North Atlantic, Geochim. Cosmochim. Acta, 42, 1501-1516, 1978.

Zindler, A., E. Jagoutz, and S. Goldstein, $\mathrm{Nd}, \mathrm{Sr}$, and $\mathrm{Pb}$ isotopic systematics in a three-component mantle: $A$ new perspective, Nature, 298, 519-523, 1982.

Zoback, M. L., and M. D. Zoback, State of stress in the conterminous United States, J. Geophys. Res., 85, 6113-6156, 1980.
N. H. Sleep, Department of Geophysics, Stanford University, Stanford, CA 94305.

(Received September 20, 1983;
revised January 23, 1984;

accepted March 1, 1984.) 